\title{
Consideraciones sobre la Reforma de la Industria Petrolera en México
} Considerations on the Reform of the Oil Industry in Mexico

\author{
Manuel Aguilera Gómez / Francisco Javier Alejo / \\ Jorge Eduardo Navarrete / Ramón Carlos Torres
}

* Profesores-Investigadores del Programa Universitario de Estudios del Desarrollo (PUED)

Grupo de Energía

Journal of Economic Literature (JEL): Q4, L71, Q48

Palabras clave: Energía

Hidrocarburos. Extracción y refinado

Política Gubernamental

Keywords:

Energy

Hydrocarbon fuels. Extraction and Refination

Government Policy

\section{Resumen}

La reforma energética significa un cambio de paradigma. Su esencia es la apertura jurídica e institucional, casi irrestricta, a la inversión privada, el repliegue en las funciones de exclusividad del Estado y la reducción del ámbito de soberanía de la Nación sobre los hidrocarburos. Sus impulsores dan por hecho una reacción favorable de la inversión privada, especialmente la extranjera, convergente además con el interés nacional. Asumen, sin demostración o evidencia, salvo recurrir a argumentos doctrinarios de mercado, que será posible maximizar la explotación de hidrocarburos, generar mayores ingresos del gobierno y revertir la tendencia decreciente del excedente petrolero. Ante la atonía crónica de la capacidad instalada de refinación y de petroquímica, se acentúa el sesgo exportador de petróleo crudo, característico del sector energético mexicano durante las últimas tres décadas. El nuevo paradigma petrolero así forjado constituye un retorno al prevaleciente hace un siglo, no muy diferente al de un enclave colonial primario exportador, soportado por la expectativa de que la inversión extranjera directa permitirá fortalecer el horizonte de explotación de los hidrocarburos.

\section{Abstract}

The energy reform constitutes a paradigmatic change. It means nearly unrestricted legal access to private investments and turns back both the exclusivity of the State in energy activities and the scope of Nation's sovereignty over hydrocarbons. The reform proponents believe as a matter of fact that private investors will react on the way they want to. A naive similar assumption was adopted regarding the convergence of both investors and Nation interests. Without demonstration, based on doctrinarian perception of the market laws, it is assumed that maximization of hydrocarbons exploitation, increased income for the government and the reversal of the present declining trend of the country's oil surplus will be in order. As a consequence of the protracted stagnation of the country's oil processing capacity (refining and petrochemicals) the reform will accentuate the crude oil exporting bias of the past three decades. The new paradigm represents a century long retrogression: a new exporting colonial enclave 
justified by the assumption that the presence of foreign investment will automatically translate into a widened hydrocarbons horizon for the country.

\section{Consideraciones iniciales}

El Poder Ejecutivo y el Congreso de la Unión culminaron, el 13 de agosto de 2014, una etapa de transformación profunda en la estructura jurídica, institucional y organizativa del Estado mexicano en materia energética, iniciada un año antes con la presentación, por parte del primero, de una iniciativa de reforma constitucional en materia de energía. En esa fecha, la Secretaría de Energía (SENER) informó haber emitido la resolución por medio de la cual asignó a Petróleos Mexicanos (Pemex), en la llamada "ronda cero", las áreas en exploración y los campos en producción de hidrocarburos que podrá seguir operando en su nueva condición de empresa productiva del Estado (EPE). Se inició así, en la práctica, la escisión de un patrimonio propiedad de la Nación en dos segmentos, uno reservado a las EPE y otro que, en sucesivas licitaciones, se pondrá a disposición de inversionistas privados y de EPE, mediante la suscripción de contratos y, eventualmente, ulteriores asignaciones a estas últimas.

$\mathrm{Si}$, como indican las cifras oficiales, al 1 de enero de 2014, el total de las reservas de hidrocarburos denominadas $2 \mathrm{P}$ puede cifrarse en 24.8 miles de millones de barriles de petróleo crudo equivalente (mmmbce) y los recursos prospectivos en $112.8 \mathrm{mmmbpce}$, las asignaciones a Pemex en la ronda cero (20.6 y $22.1 \mathrm{mmm}$ bpce, respectivamente) equivalen a $83 \%$ de las reservas $2 \mathrm{P}$ y a $20 \%$ de los recursos prospectivos. Los remanentes, $17 \%$ de las reservas $2 \mathrm{P}, 100 \%$ de las reservas posibles y $80 \%$ de los recursos prospectivos podrán distribuirse entre contratistas privados y las EPE a través de eventuales nuevas asignaciones o contratos. 1

La reforma energética emprendida por ambos poderes de la Unión consistió, en esencia, en permitir, mediante distintas modalidades, el acceso de la inversión privada nacional y extranjera a prácticamente a todas las actividades de hidrocarburos y electricidad, con algunas excepciones muy delimitadas, por ejemplo la energía nuclear. El acceso de la inversión privada se extiende además, mediante la suscripción de contratos mercantiles, a la explotación de los hidrocarburos propiedad de la Nación.

La convicción de los impulsores de la reforma es que el nuevo arreglo jurídico e institucional propiciará el fortalecimiento y creación de nuevos mercados de energía abiertos a la competencia y el repliegue del Estado a funciones de rectoría, regulación

1 Con la denominación 2P, las autoridades hacen referencia a la suma de las reservas probadas y probables. La diferencia entre ambas es el nivel de certidumbre sobre los volúmenes susceptibles de extracción. Los de las probadas han sido sujetos a un régimen de certificación y se asocian a un nivel de certeza superior a 90\%. En cambio, el nivel de probabilidad de extracción de las probables se estima en por lo menos 50\%. Por ello, la suma de volúmenes de hidrocarburos alojados en el subsuelo con esta diferencia de certidumbre de extracción debería ser vista con precaución, pues se trata de una adición de componentes heterogéneos. La situación se complica cuando se adicionan reservas posibles, cuya probabilidad es todavía inferior (cuando menos 10\%), en lo que se denomina 3P. Los recursos prospectivos son aún más inciertos, son recursos "a descubrir", que no pueden ser identificados como reservas. 
y promoción, con participación acotada en ciertos reductos de producción. Con ello, se aspira a crear condiciones de competencia y apertura para atraer inversiones privadas, intensificar la explotación de los hidrocarburos y ampliar la oferta competitiva de energéticos, en situación de mejor calidad y menores precios sin necesidad de subsidios. Todo ello, según documentos y discursos oficiales, con el consecuente impacto positivo en el crecimiento incluyente de la economía, el aprovechamiento del potencial productivo del país, la generación de empleo y el aumento de ingresos y gastos del sector público, entre diversos otros beneficios.

La energética es una, con mucho la más trascendente, de otras diez reformas estructurales que el Ejecutivo Federal ha promovido e instrumentado desde el inicio de la administración como ejes centrales de su programa de gobierno. La pretensión de ellas es remover los obstáculos de mercado que impiden mejorar la productividad de la economía y alcanzar con ello, a juicio del propio Ejecutivo Federal, el potencial máximo de crecimiento del PIB.

Según cifras de la Secretaría de Hacienda y Crédito Público (SHCP), 2 la productividad total de la economía disminuyó $0.4 \%$ anual entre 1990 y 2011 y se prevé que el crecimiento inercial del PIB para 2018 sea de 3.5\%. Sin embargo, la SHCP sostiene que, con la reforma energética, esta tasa de crecimiento se incrementará en $1 \%$ y con las otras tres reformas estructurales aprobadas (en telecomunicaciones, fiscal y financiera), se adicionará otro incremento de $0.8 \%$ (véase el cuadro 1). Al sumar la contribución de la inercia y el efecto de las reformas estructurales, la tasa anual de crecimiento del PIB se estima en $5.3 \%$ en 2018 , en vez de $3.5 \%$ (la fuente no ofrece información que sustente estas estimaciones ni las consecuencias que de ellas se desprenden).

\begin{tabular}{|c|c|c|c|c|}
\hline \multicolumn{5}{|c|}{$\begin{array}{l}\text { Cuadro } 1 \\
\text { Crecimiento potencial del PIB con reformas estructurales }\end{array}$} \\
\hline & 2015 & 2016 & 2017 & 2018 \\
\hline Crecimiento inercial & 3.8 & 3.7 & 3.6 & 3.5 \\
\hline Telecomunicaciones & 0.2 & 0.3 & 0.3 & 0.2 \\
\hline Financiera & 0.3 & 0.3 & 0.4 & 0.4 \\
\hline Energética & 0.3 & 0.4 & 0.7 & 1.0 \\
\hline Inercial más reformas & 4.7 & 4.9 & 5.2 & 5.3 \\
\hline
\end{tabular}

Fuente: PRONAFIDE 2013-2018, SHCP.

Los supuestos del razonamiento oficial, soporte de las reformas estructurales, son claramente cuestionables. Hacen suponer la existencia de un potencial de productividad total de los factores - definido, medible y objetivo-, susceptible de materializarse si se remueven los obstáculos que limitan el accionar del mercado y el acceso irrestricto de la inversión privada nacional y extranjera a todos los sectores de la economía. La vía, proponen, es flexibilizar los mercados de factores de la producción, en especial el laboral, y confinar al Estado a funciones de rectoría y regulación. La literatura económica reciente abunda en evidencias teóricas y empíricas sobre la

\footnotetext{
${ }^{2}$ Informe semanal del Vocero de la SHCP, 23-27 de diciembre de 2013.
} 
naturaleza, alcance y precariedad en que se fundamenta este razonamiento neoliberal, en ocasiones, como sucede en el país, revestido de supuesto pragmatismo o de reacción a las deficiencias históricas mostradas por el Estado para solventar las aspiraciones de crecimiento. No es propósito detenerse en estas consideraciones, lo que se desea es poner de relieve que la reforma energética, como las otras de su género, son exponentes de una convicción doctrinaria, en este caso la neoliberal, y que, quizá por ello, no se ofrecen fundamentos o argumentos que soporten el logro de los objetivos propuestos a partir de los nuevos diseños institucionales de mercado.

La reforma constitucional en materia energética de diciembre de 2013, tuvo como una de sus justificaciones principales la remoción de obstáculos para favorecer la apertura y competitividad de los mercados de energía, con el más amplio acceso a la inversión privada local y foránea. Uno de los obstáculos más visibles, reiteradamente citado por los impulsores de la reforma, fue la vigencia del principio constitucional de exclusividad de la Nación en la apropiación y aprovechamiento de los hidrocarburos y de exclusividad del Estado en las actividades productivas de energía consideradas estratégicas. La remoción de este principio constituyó la piedra angular de las modificaciones y adiciones de la Constitución promulgadas en diciembre de 2013.

Un segundo elemento fundamental de estas modificaciones, de honda incidencia en la nueva configuración de los mercados nacionales de energía, fue la mudanza de visión sobre el significado para la Nación de los recursos naturales: de ser un recurso estratégico de la Nación se tornó una mercancía o un bien cuyo mandato constitucional es incidir en los ingresos del gobierno, cuando los hidrocarburos se encuentran alojados en el subsuelo, o en los intereses del propietario de los mismos, una vez que éstos son extraídos. Mercantilizada la riqueza petrolera, las consecuencias pueden ser múltiples. Sólo se desea destacar que el espacio y los criterios de transacción y decisión de los hidrocarburos se ventilan ahora en el marco de las reglas de los mercados de energía.

\section{Evolución de la industria petrolera y de la economía mexicanas}

Entre el fin de la Segunda Guerra Mundial y la crisis del mercado petrolero internacional en los años setenta del mismo siglo, con sus secuelas de pánico y desorden económico y financiero en los mercados mundiales, numerosos países que poseían yacimientos de hidrocarburos siguieron la ruta de tomar el control de tales recursos depositándolo en manos del Estado. Hubo entre ellos países desarrollados -como Noruega - y muchos otros en desarrollo y menos desarrollados, en la terminología de Naciones Unidas. Otros lo habían hecho años antes, como México en 1938. El proceso continuó al punto de que, actualmente, alrededor de $90 \%$ del petróleo comercializado en los mercados internacionales es producido en países que han nacionalizado sus recursos de hidrocarburos, en cuyos territorios se encuentra una proporción similar de las reservas.

La mayor parte de los países involucrados escogió el camino de crear por lo menos una empresa petrolera o un ente público nacional fuerte, eficiente y dinámico encargado de la tarea y al servicio del interés nacional: autonomía energética, captura 
de la renta económica derivada de la explotación de estos recursos naturales estratégicos, así como la asignación de dicha renta a la promoción del desarrollo económico y social del país. En algunos países, México entre ellos, la empresa o ente nacional fue dotado de total exclusividad. En otros casos, los países decidieron combinar a su empresa nacional con empresas privadas nacionales e internacionales, ya fuese en asociación o en concurrencia.

Cualquiera que haya sido la ruta seleccionada, en la mayor parte de los países estuvo presente la motivación de atender un imperativo de Estado: el balance del poder. El balance de poder entre el ámbito de lo privado y el de lo público, y también entre lo nacional y extranjero.

En el caso de México el camino seleccionado fue el de otorgar exclusividad a Pemex. Durante casi medio siglo, a partir de la expropiación de 1938, el país logró los objetivos señalados, con Pemex desempeñándose como instrumento fundamental para el desarrollo. Se logró capturar la renta económica derivada de la extracción de hidrocarburos y asignarla, con éxito, a programas y proyectos de desarrollo económico y social (infraestructura básica, educación y salud pública), así como a la promoción del desarrollo agropecuario e industrial. De hecho, durante ese medio siglo el país logró la tasa de crecimiento económico promedio más alta de su historia. Se tuvo la fortuna de contar con importantes yacimientos en tierra cuyo costo de exploración y extracción era muy bajo y cuya complejidad técnica fue resuelta por el avance de la ingeniería mexicana.

Desde el principio, se decidió dedicar los recursos petroleros al consumo nacional, tanto de las empresas como de las personas. Pemex, en tanto empresa estatal y más allá de las limitaciones apuntadas en el apartado siguiente, se desempeñó con eficiencia y con una razonable autonomía, al explotar los yacimientos ya conocidos y desarrollar sus propias capacidades para el descubrimiento de nuevas reservas.

Hacia el final de los años sesenta los campos tradicionales ya habían entrado en fase de declinación. Sin embargo, en esta época Pemex fue convertido, de empresa propiedad total del Estado y con un alto grado de autonomía, en un organismo público descentralizado, incorporado al presupuesto federal. Esta decisión resultó ser, en el mediano y largo plazos, un gran error, en tanto convirtió a la empresa no solamente en subordinada de la SHCP sino, además, la expuso cada vez más a influencias e interferencias de carácter político.

Durante la primera mitad de los años setenta, se tuvo la fortuna - gracias a los continuados esfuerzos exploratorios de Pemex y la liberación de los precios internos de los combustibles, que habían permanecido congelados durante 18 años - de descubrir enormes yacimientos en aguas someras en la sonda de Campeche, con un campo súper gigante (Cantarell) que - junto con otros descubrimientos terrestres en Tabasco y Chiapas - le brindaron al país cuantiosos recursos, que le permitieron enfrentar las necesidades de mayor gasto público. Los beneficios de tales yacimientos - los marítimos y los terrestres - se siguen manifestando.

Las reservas de petróleo y gas del país súbitamente saltaron a aproximadamente 50 mil millones de barriles de petróleo crudo equivalente ( $\mathrm{mmmbpce}$ ), según 
certificación internacional obtenida hacia 1978. Pemex se convirtió de pronto en uno de los mayores entes petroleros del mundo.

El país se sumergió en el auge petrolero y la burbuja correspondiente y se cometió el error de no crear un ente autónomo cuya misión fuese administrar en favor del desarrollo el excedente de recursos provenientes de la nueva riqueza petrolera. Las consecuencias de ello son conocidas: inestabilidad macroeconómica de 1982 a 1994.

A partir de este periodo, las exportaciones se convirtieron en el fenómeno dominante, hasta alcanzar, ya en el presente siglo, niveles cercanos a 1.9 millones de barriles diarios (mmbd), con producción de $3.4 \mathrm{mmbd}$. Como consecuencia sobre todo de la declinación de Cantarell, iniciada en 2005, la extracción cayó a 2.5 mmbd y las exportaciones se desplomaron hasta 1.2 mmbd en 2013.

El país en su conjunto se había habituado a las riquezas del auge petrolero, con graves consecuencias para la estabilidad macroeconómica. De particular importancia fue que el equilibrio del presupuesto federal se había tornado dependiente de los ingresos provenientes de Pemex: entre 36 y $38 \%$ de los ingresos presupuestales. Las nuevas circunstancias políticas del país, caracterizadas por gobiernos divididos, sin mayorías parlamentarias, con la población y los tres órdenes de gobierno habituados a vivir de la renta petrolera, fue imposible construir el acuerdo político necesario para una reforma fiscal suficiente para sufragar las necesidades crecientes de gasto público, mientras en el horizonte se asomaba ya el agotamiento de los yacimientos de hidrocarburos de fácil acceso.

En los lustros recientes se dilapidó la renta económica del petróleo en una proporción significativa y, de paso, se debilitó la industria petrolera nacional cuando más se necesitaba, a fuerza de imponerle gravámenes fiscales excesivos, de interferencias burocráticas paralizantes y de influencias políticas conducentes a la corrupción.

Afortunadamente, el país todavía cuenta con una considerable riqueza en hidrocarburos, la que, sin embargo, ya no es de fácil acceso ni de bajo costo. Para aprovecharlos, se requiere fortalecer a Pemex y modernizar a la industria, sin perder de vista los objetivos nacionales ni el control soberano de la industria de los hidrocarburos ni la necesidad de mantener un adecuado balance de poder, de modo tal que los intereses particulares no prevalezcan sobre los colectivos ni los extranjeros se impongan sobre los nacionales.

En lo que constituye un nuevo episodio, como antes se dijo, en diciembre de 2013 se promulgó una reforma constitucional en materia energética que permite la participación privada en todas las áreas de la industria petrolera. En agosto de 2014 se promulgó la legislación reglamentaria respectiva, dándose por concluida la fase legislativa del proceso de reforma. ${ }^{3}$ Se anunció también el resultado de la llamada "ronda cero" que asigna a Pemex áreas de exploración y campos en producción, que constituyen su nueva base de recursos. Queda planteada la petición de consulta popular sobre el conjunto de la reforma energética, que eventualmente se realizaría en junio de 2015.

3 PUED, Grupo de Energía, "Análisis de las iniciativas de legislación reglamentaria de la Reforma Energética”, Documentos de Trabajo 11a-11d, junio-julio, 2014. 
Ningún país que se haya encontrado en una tesitura similar a la de México ha logrado avanzar debilitando a su empresa petrolera nacional. Por ello, se debe fortalecer a Pemex, como empresa nacional moderna, potente, de alta eficiencia y honestidad. Sobre esta base será posible asociarse con terceros para beneficio de México. 4

\section{Pemex: paradigmas cambiantes}

Se pasa revista, en este apartado, a los distintos paradigmas que han regido la industria petrolera en México en algo más de un siglo de existencia: el enclave exportador previo a la nacionalización, la garantía del crecimiento económico con seguridad energética, el retorno de la prioridad exportadora y el derivado de la reforma energética de 2013-2014.

\section{El enclave colonial primario exportador}

Al fundarse la República, prevaleció el principio establecido en la legislación minera en el sentido de que los recursos del subsuelo pertenecían a la Nación. Ochenta años después, aprovechando la influencia política del secretario de Hacienda, José Ives Limantour, los inversionistas extranjeros lograron que el presidente Díaz reformase el régimen legal imperante para conceder a los dueños de los terrenos la propiedad, entre otros recursos, de los yacimientos de petróleo. Esta reforma, promulgada en 1901, homologaba el régimen nacional con las normas anglosajonas, con el propósito de alentar la inversión de capital extranjero en la actividad petrolera. En efecto, a raíz de esta reforma "modernizadora", varias empresas estadounidenses e inglesas se interesaron en explotar las "chapopoteras" localizadas en la región Huasteca y en el sur de Veracruz.

En los primeros diez años de actividad, ya se habían instalado una veintena de empresas en las zonas productoras potenciales, escenario de todo género de abusos - ampliamente documentados - en perjuicio de los propietarios rurales en áreas donde se presumía la existencia de mantos petrolíferos. "O me vendes tu terreno o se lo compraré a tu viuda" fue el lema popularizado en las zonas petroleras, de las que comenzaron a extraerse gigantescos volúmenes de crudo, al extremo que México se convirtió, a principios de los años veinte, en el segundo país productor mundial de crudo. 5

Encabezadas por la subsidiarias de la Standard Oil y la Royal Dutch Shell, las firmas extranjeras emprendieron una lucha frontal en contra de las disposiciones contenidas en el artículo 27 constitucional de la Constitución de 1917, que restablecía el principio de que los recursos del subsuelo eran propiedad de la Nación. La batalla no se desplegó en los tribunales sino en la arena política. Inconformes con las disposiciones constitucionales, además de una campaña publicitaria a escala mundial, las

4 F. J. Alejo, "Reforma Energética y Fiscal en México", Cuadernos de Investigación en Desarrollo, núm. 3, PUED, UNAM, México, 2014.

5 Daniel Yergin (1992), La Historia del petróleo. La lucha voraz por dinero y el poder desde 1853 hasta la Guerra del Golfo, Javier Vergara Editor, Buenos Aires, Madrid, México, Santiago de Chile. 
empresas financiaron un contingente armado, de más de diez mil efectivos al mando del "general" Manuel Peláez, organizado para proteger las instalaciones petroleras. Las zonas petroleras quedaron convertidas en enclaves territoriales, con el propósito de instituir un nuevo Estado nacional en el norte del país, apoyado por fuerzas estadounidenses, emulando la segregación de Panamá de la soberanía de Colombia - consumada quince años antes - para crear la Zona del Canal. La intentona fue frustrada por la amenaza del presidente Calles de incendiar las instalaciones petroleras en la eventualidad de una invasión armada.

La producción nacional comenzó a declinar en virtud del agotamiento de los yacimientos petroleros de la Faja de Oro en el norte de Veracruz y al menor interés por las nuevas exploraciones a causa del declive de los precios internacionales y la Gran Depresión. En estas condiciones, el interés de las empresas se orientó a la instalación de refinerías para aprovechar el incipiente - pero promisorio- consumo nacional de petrolíferos como gasolina y combustóleo.

En los años treinta, al amparo de la política de fortalecimiento a los sindicatos, se logró constituir el Sindicato Nacional de Trabajadores Petroleros de la República Mexicana (STPRM) que planteó la negociación colectiva de trabajo con todas las empresas petroleras en 1937. Se emprendió un complejo proceso de negociación obrero-patronal que resultó infructuoso y culminó con la negativa -impregnada de soberbia- de las compañías petroleras a acatar la resolución en materia laboral dictada por la Suprema Corte de Justicia de la Nación, lo que obligó al presidente Cárdenas a expropiarlas. Fue un acto de dignidad nacional que mereció el generalizado respaldo popular, incluso de las altas jerarquías eclesiásticas. Era el punto de partida para instaurar una nueva etapa en la vida del país. ${ }^{6}$

\section{Seguridad energética para el crecimiento}

Inmediatamente después de la expropiación, el STPRM encargó a cada una de sus secciones organizar el trabajo de extracción, refinación y transporte para mantener la normalidad en las actividades de la industria. El Gobierno, a través de la Distribuidora de Petróleo -órgano gubernamental - se hizo cargo de las labores de comercialización de productos petrolíferos en el país y en el exterior. La administración gubernamental encaró dos frentes: el nacional, tendiente a contener las exigencias sindicales, y el internacional, relacionada con el bloqueo comercial y el pago de las indemnizaciones a las compañías expropiadas.

Insatisfechos con tener sólo tres de nueve asientos en el Consejo de Administración de la nueva empresa - Pemex - el STPRM pretendía instaurar la autogestión obrera. Al advertir la imposibilidad de lograrla, emprendió una sistemática confrontación con los encargados de la administración gubernamental, actitud que desembocó en varios movimientos huelguísticos de alcance parcial, acudiéndose a las fuerzas armadas con la encomienda de "preservar las instalaciones".

6 Lázaro Cárdenas (1972), Obras I Apuntes 1913-1940, unAM, México p. 388. 
Las grandes empresas petroleras ejercieron todo género de presiones para imponer un bloqueo comercial que impidiera a Pemex el acceso a materias primas fundamentales como el tetraetilo de plomo, insumo esencial para la formulación de gasolinas. Al mismo tiempo interpusieron todo género de recursos para incautar -infructuosamente- el petróleo colocado en los mercados foráneos. El advenimiento de la Segunda Guerra Mundial y la actitud del presidente Roosevelt de reconocer el derecho del gobierno mexicano a aplicar la expropiación favorecieron un acuerdo, primero con las empresas de Estados Unidos (1941) y después con las inglesas (1948).

Desde un principio, la política petrolera pretendió armonizar cinco objetivos difícilmente conciliables: aumentar las exportaciones de crudo para aliviar las presiones sobre la balanza de pagos; preservar la tasa de restitución de reservas; hacer frente a la acelerada demanda interna de productos petrolíferos; contribuir al combate de las presiones inflacionarias y al desarrollo industrial mediante precios subsidiados de combustibles, y entregar al gobierno contribuciones fiscales para aliviar la penuria presupuestal. Pesaba sobre la actividad petrolera una carga descomunal.

Durante sus primeros 35 años de existencia, Pemex logró superávit en la balanza comercial petrolera; preservó el nivel de las reservas en proporción a 20 años de extracción; consiguió satisfacer con producción interna más de $90 \%$ de la demanda nacional de petrolíferos; sostuvo los precios de venta de los combustibles por debajo de los imperantes en el mercado estadounidense, y cubrió tributaciones equivalentes a $20 \%$ de sus ventas, que representaron $12 \%$ de los ingresos presupuestales del gobierno federal. Todas estas medidas habrían de significar sacrificios que gravitaron sobre la situación financiera de la paraestatal y minaron su capacidad de inversión. Se había convertido en una institución productiva con fines de fomento.

La máxima extracción y sus consecuencias sobre el crecimiento

A mediados de los años setenta, los hallazgos petroleros en las costas de Tabasco y Campeche cambiaron las premisas de la política económica; despertaron la ambición de aumentar la extracción de crudos para colocarlos en un mercado mundial al alza. Se abandonó el paradigma de la seguridad energética y se optó por el de la máxima extracción en aras de conseguir la autosuficiencia financiera.

En breve plazo, el auge petrolero llegó a su fin con la crisis cambiaria de 1982. Se había probado que el aparato productivo nacional, tanto en el terreno manufacturero como en la producción de alimentos, era incapaz de producir al ritmo impuesto por la demanda agregada. Las principales aduanas terrestres y marítimas estaban congestionadas permanentemente por las crecientes importaciones; la inflación se aceleraba y el peso se sobrevaluó. A raíz de la detención de la carrera alcista del precio internacional del petróleo, se contrajo la oferta de financiamientos internacionales y apareció la negativa a la renegociación de los créditos vencidos. Siempre solidarias con sus propios intereses, las clases pudientes se apresuraron a situar sus ahorros líquidos en bancos foráneos. La fuga de capitales alcanzó dimensiones descomunales. 
Esta crisis abrió las puertas a los patrocinadores del cambio de rumbo 7 y dio cabida a los nuevos paradigmas de la política económica: libertad de mercado y reducción de la presencia del Estado en la economía. A partir de 1983, se abolieron los instrumentos de fomento económico en atención a la tesis de que "el mejor gobierno es el que menos interfiere en la vida económica"; mediante la incorporación al GATT, se instauró una política comercial de apertura unilateral, y, al mismo tiempo, se enajenaron diversos activos públicos: la banca comercial, el servicio de telefonía fija, las empresas de aviación, las empresas fabricantes de textiles, automotores, maquinaria y otros bienes de capital, productos siderúrgicos, la compañías mineras, la cadena hotelera más grande del país, entre otras. Únicamente el sector energético escapó a esta febril campaña privatizadora, pese a las reiteradas presiones ejercidas por el gobierno estadounidense previas a la firma del TLCAN. ${ }^{8}$ En el fondo, se iba incubando una versión "tropicalizada" del síndrome holandés. Se privilegiaba la explotación petrolera y se ignoraban las actividades manufactureras y la producción de alimentos. Se iniciaba la etapa de la desindustrialización progresiva y de creciente dependencia alimentaria.

Agobiadas por la crisis de 1995, las autoridades financieras buscaron en las mayores exportaciones de crudo la solución al desequilibrio fiscal y de balanza de pagos. Sin embargo, esas exportaciones no se sustentaron en nuevas áreas de producción sino en la sobreexplotación de las existentes, en especial Cantarell, yacimiento de hidrocarburos catalogado entre los más grandes del mundo. Al mismo tiempo, se elevó la carga fiscal sobre los ingresos de Pemex y se entregó la factura petrolera como garantía de pago al gigantesco préstamo concedido al gobierno mexicano por el Departamento del Tesoro, como parte del programa convenido con el Fondo Monetario Internacional y otras instituciones internacionales, destinado a solventar los compromisos con acreedores externos.

Este conjunto de decisiones dio lugar al estrangulamiento financiero de Pemex, ante lo cual el gobierno federal optó por explorar formas de financiamiento extrapresupuestal de las inversiones de la paraestatal. Así nacieron, entre otros instrumentos financieros, los Proyectos de Inversión de Registro Diferido en el Gasto (PIDIREGAS). Además de oneroso, este sistema obligó a contratar obras "llave en mano" sin requisito alguno sobre contenido nacional, afectando la capacidad técnica y de ejecución de Pemex. Conscientes de su oneroso costo, años después las autoridades hacendarias consolidaron esa deuda en bonos y otros instrumentos colocados en los mercados financieros internacionales. ${ }^{9}$

\footnotetext{
7 Miguel De la Madrid (2004), Cambio de rumbo, Fondo de Cultura Económica, México.

8 Carlos Salinas de Gortari (2000), México, un paso difícil a la modernidad, Plaza\&Janés Editores. S.A. Barcelona, España. pp. 81 y ss.

9 Véanse los informes a la Securities and Exchange Commission de Estados Unidos. En Pemex, relación con inversionistas, información a la SEC. http://www.ri.pemex.com/index.cfm?action=conte nt\&section $I D=17 \&$ cat $I D=12160$.
} 
Con la declinación de la producción de Cantarell, las exportaciones de crudo comenzaron a descender en forma drástica, en casi 700 mbd. Esta declinación no tuvo consecuencias catastróficas en el fisco y en la balanza de pagos gracias a la súbita y prolongada elevación de los precios internacionales de crudo, a la entrada en producción de otros campos, y al estrangulamiento financiero de la paraestatal, al extremo de colocarla en situación deficitaria. En los últimos diez años, de acuerdo con sus balances, Pemex acumuló resultados negativos que afectaron su patrimonio por 288 mil millones de pesos. Además, los saldos en el terreno comercial son en extremo preocupantes: la balanza comercial de petrolíferos es crecientemente adversa a causa principalmente de las importaciones masivas de gasolinas que cubren casi la mitad del consumo nacional; la balanza comercial de productos petroquímicos es todavía levemente superavitaria. Por su parte, la tasa de restitución de reservas es peligrosamente declinante (67.8\% en 2013). Todas estas tendencias son obra de decisiones tomadas desde la perspectiva de las finanzas del Estado, agravadas por fenómenos de otro orden como la corrupción, el desarreglo operativo-contractual y el ineficiente control interno de la empresa.

Con el ánimo de superar la situación imperante, el presidente Enrique Peña Nieto, con el respaldo de su partido y de otros partidos de derecha, plantearon al Congreso un conjunto de reformas a la Constitución y a numerosas leyes reglamentarias que, en materia de hidrocarburos, ofrecen esta actividad a los capitales privados, desde la extracción de crudo y gas hasta su industrialización y comercialización.

En materia de extracción, las normas legales establecen asignar a Pemex los campos actualmente en explotación y las áreas de exploración que esté en capacidad de desarrollar ("ronda cero"). Por otra parte, la Comisión Nacional de Hidrocarburos ( $\mathrm{CNH}$ ) licitará, en forma gradual, los yacimientos restantes mediante cuatro tipos de contratos. Los planes gubernamentales asignan a Pemex la responsabilidad de conservar su actuales niveles de producción (alrededor de 2.5 millones de barriles diarios) y aspiran a conseguir un aumento de la producción de petróleo en 500 mil barriles diarios adicionales en los próximos cuatro años, mediante contratos con empresas privadas.

Igualmente, la ampliación de la capacidad de refinación y la expansión de la petroquímica, así como la extensión de la red de gasoductos y poliductos, depende del entusiasmo empresarial al que, de manera simultánea, se confiere la posibilidad de importar directamente gas, productos petrolíferos y petroquímicos, los que serían comercializados por redes privadas de distribución. Es decir, la apertura del sector energético consumada por la vía legal es mucho más amplia que la solicitada en las negociaciones del TLCAN, sin reciprocidad.

Adicionalmente, el objetivo de maximizar los recursos provenientes de los hidrocarburos, en especial de la venta de crudo en el exterior, se conecta con la intención de continuar utilizando los excedentes así generados como ancla de un coeficiente impositivo bajo, en ausencia de una reforma hacendaria integral. 
¿Acaso estas reformas por sí mismas van detener el proceso de desindustrialización en el que está inmersa la economía nacional? ¿Van a detener las descomunales importaciones de alimentos que nos han colocado como el tercer importador mundial de granos alimenticios en el mundo? La reforma energética no persigue cambiar el rumbo de la política económica, sino es un esfuerzo desesperado por imprimir dinamismo a una economía condenada al estancamiento secular por obra del desmantelamiento de los instrumentos de fomento económico y la apertura comercial indiscriminada. Al amparo de la consigna de abatir las estructuras monopólicas, se ha emprendido un esfuerzo por dar oxígeno a un modelo de política económica probadamente ineficaz.

\section{Objetivos estratégicos de la reforma y expectativas de cumplimiento}

Los mercados nacionales de energía - como se señaló en el apartado inicialcomprenden los múltiples eslabones de la cadena productiva de los hidrocarburos. Como se ha dicho, sus características principales de operación han sido definidas con las disposiciones legislativas emitidas por el Congreso, a iniciativa del Ejecutivo Federal, y por las decisiones de éste último, emanadas de sus propias decisiones legislativas. No obstante, el marco formal regulatorio, institucional y operativo de esos mercados contrasta con la realidad prevaleciente. Su instrumentación no sólo es una cuestión de tiempo. El tránsito para instalar el nuevo marco contiene incertidumbres, además de las que el mismo proceso formal ha dejado sin responder. Este conjunto de circunstancias imprime peculiaridades a dichos mercados que merecen ser ponderadas si se analiza la viabilidad de que la reforma permita alcanzar los resultados que se espera de ella.

\section{Resultados esperados de la reforma}

Precisar las expectativas y los resultados que se espera obtener con la reforma energética no es sencillo. La información disponible está contenida en el programa de gobierno de la actual administración, las exposiciones de motivos de las iniciativas de reforma constitucional y de legislación regulatoria, el Plan Nacional de Desarrollo (PND) 2013-2018 y la Estrategia Nacional de Energía (ENE) 2014-2028, así como la edición anterior a ésta correspondiente al período 2013-2027, entre otros textos. La información coincide en el señalamiento de objetivos y metas puntuales, especialmente en lo que hace a hidrocarburos. Sin embargo, a partir de ellos se estructuran deducciones simplistas sin suficiente soporte; la dificultad de su comprensión estriba en la superficialidad de argumentos y en la recurrencia de formular propósitos sin precisar los instrumentos o mecanismos que pueden hacer viable la conversión de objetivos en realidades. El mejor ejemplo es la mención reiterada en los documentos de que una mayor extracción de hidrocarburos debido a la participación de la inversión privada incrementa los ingresos del gobierno federal y ello incide finalmente en el crecimiento 
incluyente de la economía; a mayor abundamiento se señalan cifras precisas, de nuevo sin sustento, para finalmente establecer metas de la reforma energética.

Los beneficios esperados de la reforma energética son numerosos y cubren múltiples aspectos de la economía y el bienestar social. El cuadro 2 ofrece una selección de ellos. Los renglones del cuadro se eligieron por la precisión cuantitativa de la información disponible o su importancia para comprender la lógica de la reforma energética. Se excluyen, por ejemplo, los beneficios que se relacionan con la aplicación del gasto público derivado de un eventual incremento de los ingresos del gobierno, atribuibles a su vez a una más intensa explotación de los hidrocarburos.

\begin{tabular}{|c|c|}
\hline \multicolumn{2}{|c|}{$\begin{array}{l}\text { Cuadro } 2 \\
\text { Objetivos principales de la Reforma Energética }\end{array}$} \\
\hline Indicador & Objetivo, meta o resultado esperado \\
\hline $\begin{array}{l}\text { Extracción de } \\
\text { hidrocarburos }\end{array}$ & $\begin{array}{l}\text { 2018: Petróleo crudo } 3 \text { millones de barriles diarios } \\
\text { 2018: Gas } 8 \text { mil millones de pies cúbicos diarios } \\
\text { 2025: Petróleo crudo } 3.5 \text { millones de barriles diarios } \\
\text { 2025: Gas } 10.4 \text { mil millones de pies cúbicos diarios }\end{array}$ \\
\hline $\begin{array}{l}\text { Reservas probadas } \\
\text { de hidrocarburos }\end{array}$ & Restitución anual de al menos $100 \%$ \\
\hline $\begin{array}{l}\text { Balanza externa } \\
\text { de hidrocarburos }\end{array}$ & Mantener superávit \\
\hline $\begin{array}{l}\text { Seguridad energética } \\
\text { nacional }\end{array}$ & $\begin{array}{l}\text { Abasto eficiente del mercado nacional de petrolíferos, gas y electri- } \\
\text { cidad }\end{array}$ \\
\hline Exportación de crudo & $\begin{array}{l}\text { Maximizar exportación: objetivo implícito en la meta de extracción de } \\
\text { crudo }\end{array}$ \\
\hline $\begin{array}{l}\text { Precios de energía } \\
\text { al consumidor }\end{array}$ & $\begin{array}{l}\text { Precios competitivos y eliminación de subsidios } \\
\text { Reducción de precios de gas y energía eléctrica (imprecisión en ga- } \\
\text { solinas, diesel y gas licuado de petróleo) }\end{array}$ \\
\hline Equilibrio ecológico & $\begin{array}{l}\text { Proteger el medio ambiente y reducir emisiones de GEI } \\
\text { Aumentar la participación de fuentes renovables }\end{array}$ \\
\hline $\begin{array}{l}\text { Participación } \\
\text { de la industria nacional }\end{array}$ & $\begin{array}{l}\text { Meta: componente nacional de } 35 \% \text { en los contratos de explotación } \\
\text { de los hidrocarburos }\end{array}$ \\
\hline $\begin{array}{l}\text { Ingresos del gobierno } \\
\text { por la explotación } \\
\text { de hidrocarburos }\end{array}$ & $\begin{array}{l}\text { Maximizar las contraprestaciones de contratos y derechos en asig- } \\
\text { naciones }\end{array}$ \\
\hline Crecimiento del PIB & $1 \%$ adicional en 2018, 2\% adicional en 2025 \\
\hline Empleo & $\begin{array}{l}\text { 2018: } 0.5 \text { millones, nuevos puestos de trabajo } \\
\text { 2025: } 2.5 \text { millones, nuevos puestos de trabajo }\end{array}$ \\
\hline
\end{tabular}

El conjunto de indicadores permite apreciar que el núcleo central de ellos, del que derivan los demás beneficios, objetivos y metas, es la explotación de los hidrocarburos. En efecto, el PND señala que el suministro y uso de energía es fundamental para las actividades productivas y la satisfacción de las necesidades de la población, por lo 
que sus objetivos, estrategias y líneas de acción asignan alta prelación al abasto de la demanda nacional de petróleo crudo, gas natural y petrolíferos (no se hace referencia explícita al objetivo de abastecer el mercado externo). Por ello, añade, es necesario ampliar la capacidad del Estado en la exploración y producción de los hidrocarburos -incluidos los de yacimientos no convencionales - , fortalecer la capacidad de ejecución de Pemex e incrementar las reservas de hidrocarburos y su tasa de restitución.

Los nuevos mercados de petróleo

Con la reforma energética, la cadena de la industria petrolera mexicana se estratifica en varios mercados relativamente diferenciados. Los alcances de participación de Pemex, y en algunos de esos mercados también de la CFE, son y serán definidos por el Ejecutivo Federal, con cierto rango de discrecionalidad directa o indirecta. Así quedó formalmente establecido en la legislación energética, a pesar de la presencia formal de órganos con autonomía de gestión y de los mecanismos de coordinación instituidos en las decisiones fundamentales del sector. Varias situaciones ejemplifican lo anterior: ritmo y alcance de las licitaciones para exploración y extracción, otorgamiento de permisos en refinación, política de exportación de hidrocarburos.

La configuración del mercado de exploración y extracción de hidrocarburos en la nueva modalidad instituida por la reforma energética permite hacer algunas consideraciones sobre las condiciones y requisitos que deben cumplirse para alcanzar los objetivos y metas esperados.

En ese mercado es esencial tener noción cierta del grado de certidumbre y conocimiento sobre los recursos alojados en el subsuelo. Se señala lo anterior porque se ha vuelto frecuente en el país sumar sin rigor reservas y recursos petroleros sin tomar en consideración los factores de incertidumbre y riesgo que se asocian a su explotación. En lo que hace a las reservas probadas y certificadas por instituciones reconocidas en los mercados internacionales del petróleo, al finalizar 2013 éstas ascendieron a 13.4 miles de millones de barriles de petróleo crudo equivalente $(\mathrm{mmm}$ bpce); existe certidumbre suficiente sobre la estimación de dicho volumen y sobre las posibilidades de extracción. Con base en reglas de los mercados financieros internacionales se estima que el valor presente neto de los ingresos netos derivables de la explotación de dichas reservas fue de 81 mil millones de dólares en 2013, calculado con los procedimientos metodológicos y parámetros recomendados y establecidos para estos propósitos por la Securities and Exchange Commision de Estados Unidos (véase el Cuadro 3). 


\begin{tabular}{|l|l|l|l|}
\hline $\begin{array}{l}\text { Cuadro } 3 \\
\text { Flujo neto descontado de las reservas de hidrocarburos } \\
\text { (miles de millones de dólares) }\end{array}$ \\
\hline & 2013 & 2012 & \\
\hline Ingresos futuros & 931.9 & 974.4 & $1,004.1$ \\
\hline Costos futuros de producción & -135.2 & -124.5 & -118.1 \\
\hline Costos futuros de desarrollo & -46.3 & -46.1 & -38.5 \\
\hline Flujo antes de impuestos & 750.3 & 803.8 & 847.4 \\
\hline Impuestos futuros & -634.4 & -664.3 & -649.0 \\
\hline Flujo después de impuestos & 116.0 & 139.4 & 198.4 \\
\hline Efecto de descuento (tasa & -35.0 & -41.9 & -60.5 \\
\hline $10 \%)$
\end{tabular}

Fuente: Reporte anual de Pemex a la SEC (FORM 20-F), 2013.

La cifra para 2013 es sensiblemente inferior a la estimación de los dos años precedentes, lo cual se atribuye en una pequeña proporción a la reducción de las reservas registrada al concluir ese año, pero en su parte más significativa se deriva de las expectativas de menores precios internacionales de los hidrocarburos y de mayores costos de producción y desarrollo por parte de la empresa. Todo parece indicar que este conjunto de factores adversos en la valoración de las reservas probadas continuará en los años futuros.

Los campos en producción asignados en la ronda cero a Pemex se asocian a $96 \%$ de las reservas probadas; el restante $4 \%$ se entiende que dará lugar a la suscripción de contratos de extracción con particulares o nuevas asignaciones. El significado de estas asignaciones es crucial para el futuro del país en el corto y mediano plazos. Al ritmo de producción de 2013 y suponiendo que a partir de 2018 se cumplan las metas de gobierno en materia de extracción, entonces en 2022 se habrá extraído un volumen de hidrocarburos equivalente al de las reservas actuales de que dispone el país, con el consiguiente requerimiento de restitución; si a lo anterior se añade la meta de extracción de 2025, la exigencia de restitución de reservas es aún mayor y creciente (véanse las gráficas 1a y 1b). 


\section{Gráfica 1a}

Requerimiento anual de restitución a $100 \%$

(miles de millones de barriles de petróleo crudo equivalente)

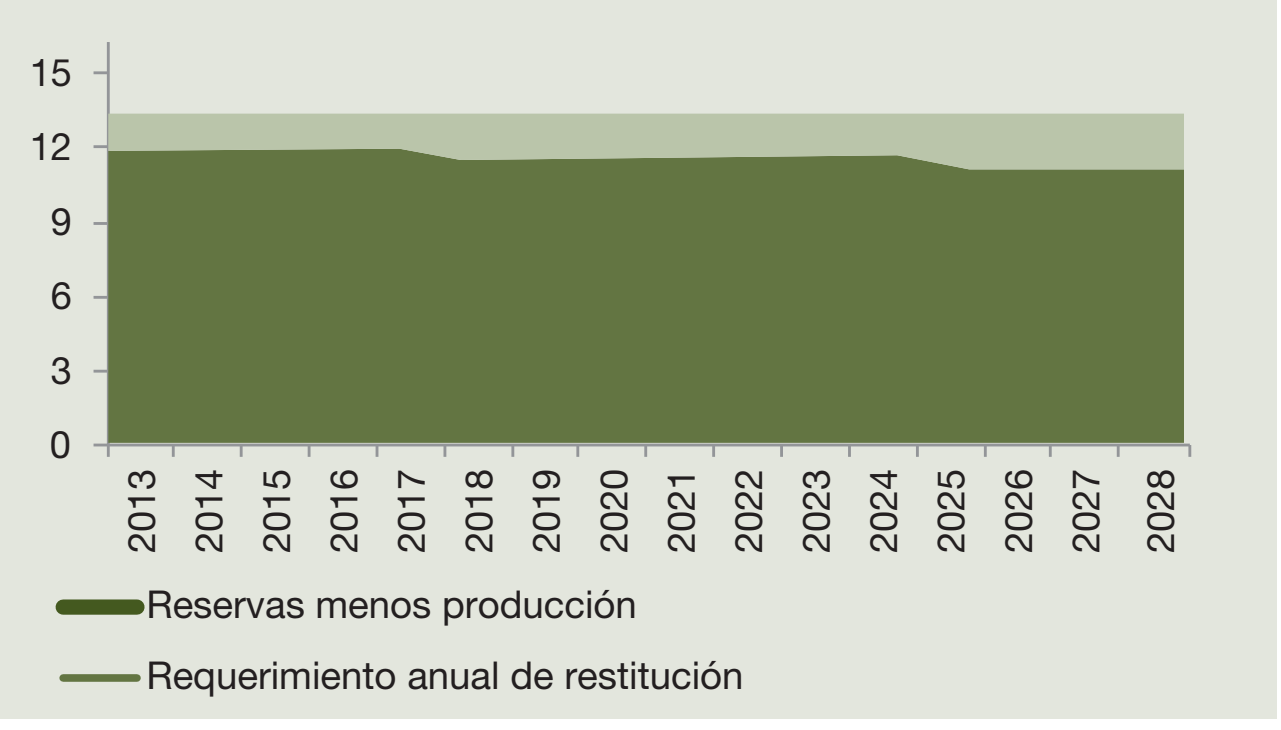

Gráfica 1B

Requerimiento acumulado de reservas probadas, restitución a $100 \%$ (miles de millones de barriles de petróleo crudo equivalente)

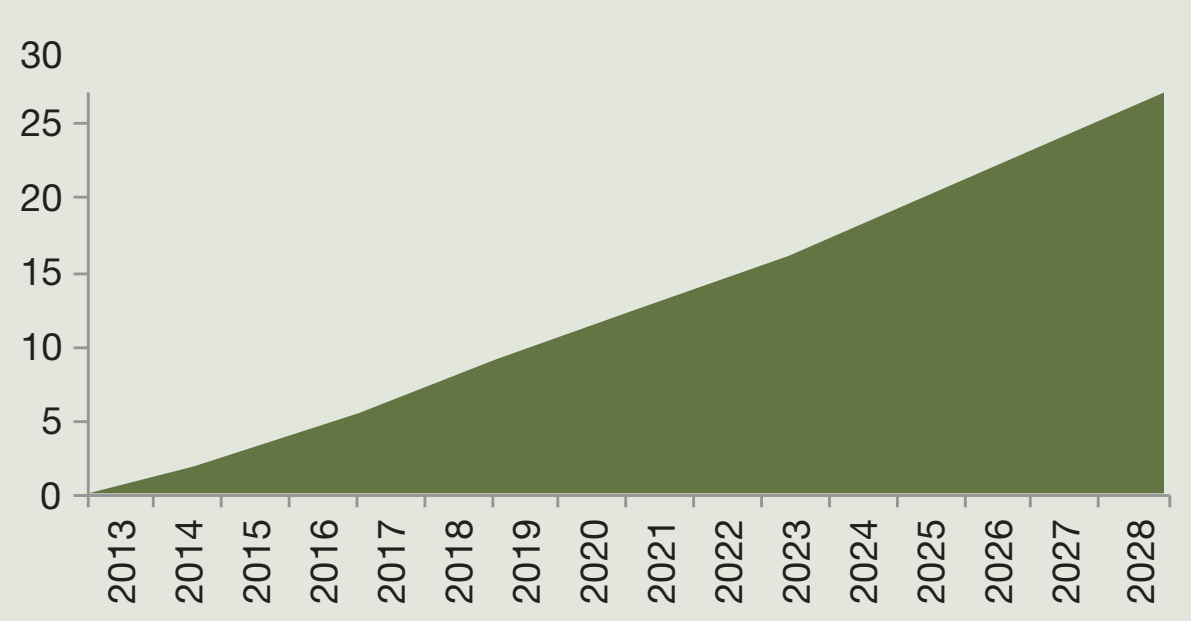

Requerimiento acumulado de restitución

Cumplir con la meta de restitución de reservas a 100\% implica incorporar a reservas probadas, antes de 2022, un volumen equivalente a la totalidad de las probables (11.4 mmmbpce) más una fracción de las posibles (2.0 de 19.0 mmmbpce) o quizá de recursos prospectivos si se materializan en reservas (véase la gráfica 2). 


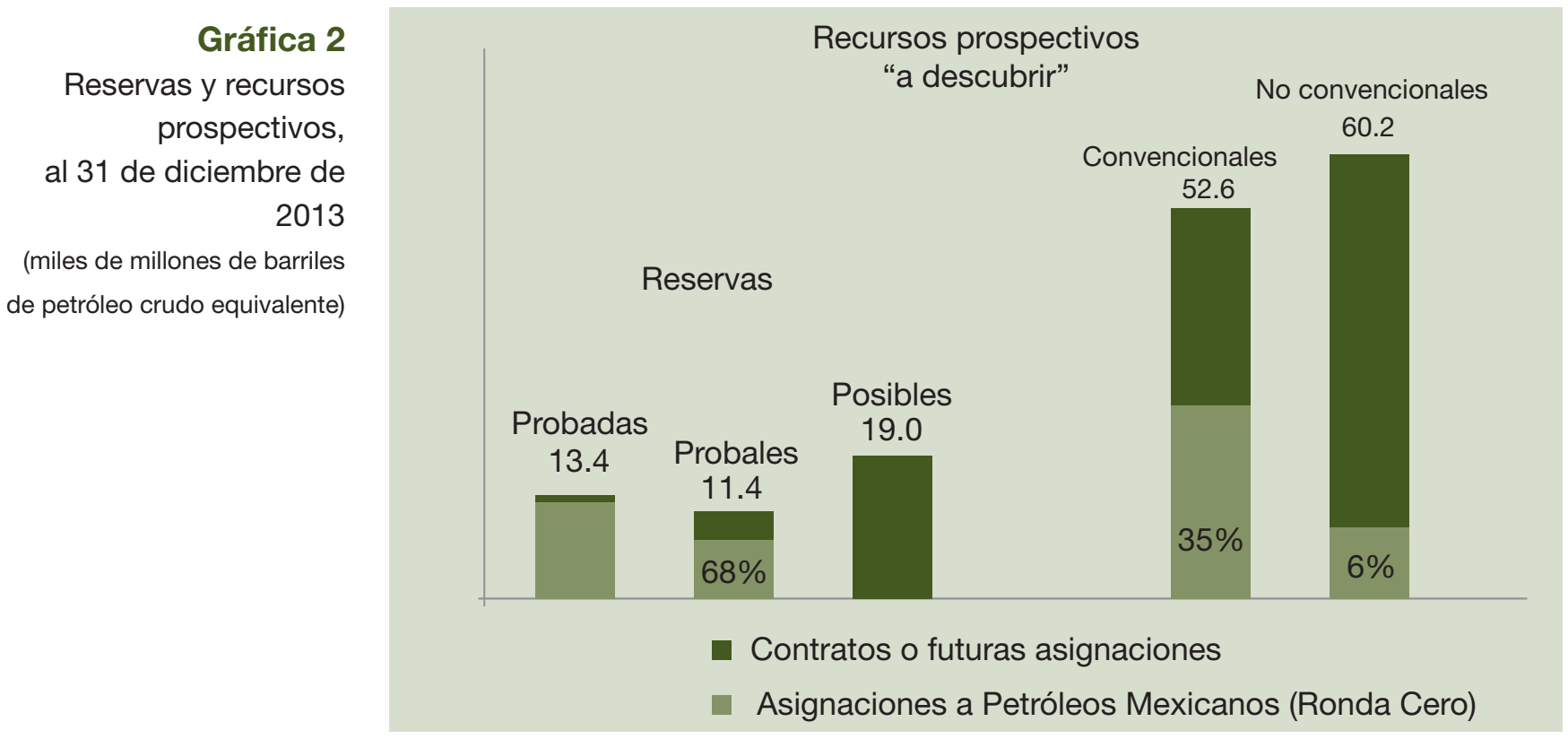

A Petróleos Mexicanos se le asignaron campos en producción que cubren, como se dijo, el $96 \%$ de las reservas probadas, $68 \%$ de las probables y $0 \%$ de las posibles; respecto a recursos prospectivos (véase de nuevo la gráfica 2) se le asignaron $35 \%$ de los convencionales (incluye aguas profundas) y $6 \%$ de los no convencionales (formaciones de lutitas principalmente).

Se colige que las partes no asignadas a Pemex de reservas y recursos prospectivos serán motivo de contratación con empresas privadas. Es decir, el acento está puesto en que Pemex continúe con la extracción al máximo y que la expectativa de restitución de reservas y ulterior extracción corresponda más a la contratación con inversionistas privados. Es evidente la brecha entre las metas de extracción y restitución, por una parte, y los plazos que requiere la incursión en las reservas no probadas y los recursos prospectivos.

Una conclusión es evidente. La persistencia en más de tres décadas de exportar al máximo petróleo crudo, a pesar de la disminución de las reservas y hasta ahora la creciente dificultad de restituirlas, ocasiona que en fecha no distante, a partir de 2022, puede que sea necesario importar crudo para operar el sistema nacional de refinación (véase la gráfica 3 ). 


\section{Gráfica 3 \\ Reservas probadas sin restitución \\ (miles de millones de barriles de petróleo crudo equivalente)}

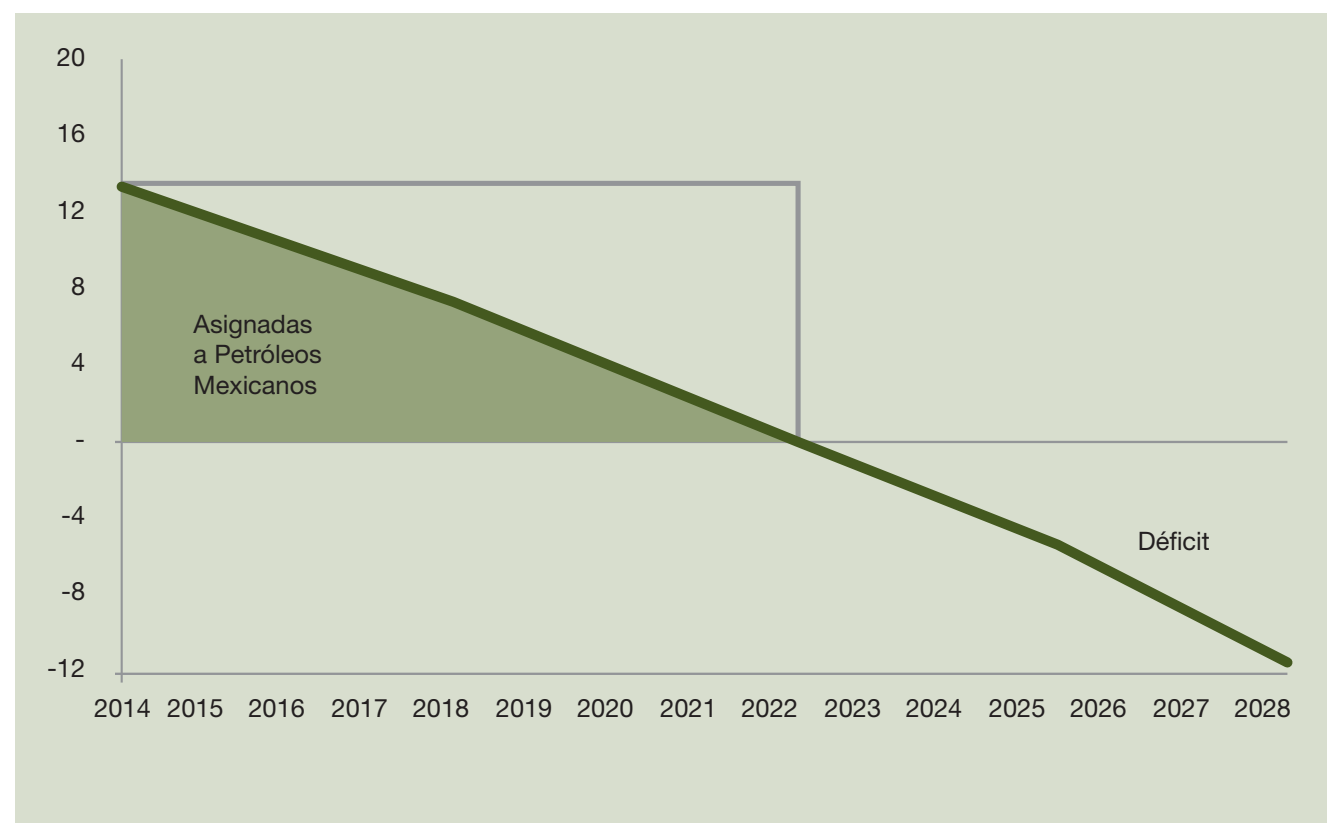

La meta de la reforma energética es ampliar las reservas, y mientras eso se logra, se instrumenta la reforma y se obtienen los resultados esperados, sin embargo, se debería revisar la política de exportación de crudo.

\section{Régimen fiscal para los hidrocarburos}

\section{Consideraciones generales}

La Ley de Ingresos sobre Hidrocarburos aborda tres cuestiones interrelacionadas: primero, define y especifica el régimen fiscal aplicable a las asignaciones -correspondiente a las EPE - y a los contratos - correspondiente a empresas particulares, nacionales y extranjeras, y a las EPE cuando sigan la vía de los contratos para exploración y explotación de hidrocarburos. Se distingue entre los derechos a cargo de los asignatarios - las EPE: Pemex y otras - y las contraprestaciones a cargo de contratistas, así como los impuestos a que ambos estarán sujetos; segundo, establece disposiciones sobre supervisión de los contratos, a cargo de la SHCP y de la CNH; y, tercero, fija las obligaciones en materia de transparencia y rendición de cuentas de asignatarios y contratistas.

Preocupa, en primer término, la concurrencia de distintos órganos públicos - SHCP, SENER, CNH, FMP y CRE - al fragmentarse y distribuirse facultades y atribuciones de aspectos patrimoniales, técnicos, operativos y financieros de los contratos y asignaciones. Se pretende que con este entramado quedará establecido un sistema de verificaciones y equilibrios ("checks and balances", según reza el original en inglés) entre órganos públicos que permitirá, al mismo tiempo, elevar la eficiencia, evitar la corrupción y bloquear las influencias políticas entre los órganos e instituciones 
involucrados. El entramado ofrece tanta preocupación que hubo de crearse una ley de órganos autónomos coordinados, refiriéndose a la CNH y la CRE. Los requerimientos de información operativa y financiera y el volumen y frecuencia de la misma, requerida en especial para la SHCP, deja la impresión de un exceso de supervisión y de carga administrativa para las EPE, sobre todo en materia operativa.

Preocupa también que sin participación del Congreso se decidan caso por caso las contraprestaciones aplicables a los contratos, bajo el solo arbitrio de la SHCP y sin definición clara anticipada de umbrales de aceptabilidad. De ahí la importancia crítica de que la "variable de adjudicación" quede incluida en los términos públicos de las licitaciones.

La rigidez con que se define el régimen de derechos aplicable a las EPE pone en evidencia la centralidad otorgada al logro de la estabilidad fiscal del país. Esto contrasta con la casuística administrativa aplicable a los contratos con particulares -muchos de los cuales estarán lejos de ser instituciones de beneficencia-y resulta discriminatorio para las EPE, en tanto en su caso no se atiende, como en el otro, a las "condiciones del mercado". La única justificación que se esgrime es la necesidad de obtener cada año para el fisco federal, al menos, $4.7 \%$ del PIB hasta 2018. Es decir, Pemex aparece de nuevo como nodriza del fisco. En todo caso, debe reconocerse que el Fondo Mexicano del Petróleo (FMP) debió crearse desde 1977 con un diseño adecuado para evitar la dilapidación del excedente petrolero.

\section{Régimen de derechos y contraprestaciones}

El régimen de derechos aplicables a las EPE fue significativamente modificado en la Ley de Ingresos sobre Hidrocarburos aprobada en comparación con el que se proponía en la iniciativa presidencial. En primer término, el número de derechos a pagar por las EPE se redujo de nueve a tres. Se adicionó un impuesto, con base en las superficies asignadas, sobre la actividad de exploración y sobre la actividad de extracción (ambos se aplicarán también a los contratos). En segundo término, el nivel de los gravámenes se redujo, en especial el del antiguo "derecho ordinario", llamado ahora "derecho por utilidad compartida", cuya tasa se movió de $71.5 \%$ del excedente de operación (calculado con base en deducciones autorizadas) a 65\%. A éste derecho se suman los de "extracción de hidrocarburos" y de "exploración de hidrocarburos".

Otra mejoría para las EPE consiste en que el tope máximo para la suma de las deducciones ascendió de 6.5 a 12.5\% del valor del crudo extraído. Los otros dos derechos implican gravámenes moderados. Lo mismo sucede con los derechos y deducciones aplicables al gas natural asociado y no asociado. El régimen de derechos es en general más moderado al tratarse de campos complejos.

Con todo y lo positivo - si bien insuficiente- que parece, lo anterior se desvanece con lo dispuesto en el artículo transitorio segundo de la Ley, que pospone la aplicación de tales mejoras hasta después de 2018. En tal artículo transitorio se establece que la tasa del "derecho por utilidad compartida" aplicable en 2015 será de $70 \%$ (y no de 65\%) con descenso progresivo hasta alcanzar 66.25\% en 2018. Además, el 
total de deducciones autorizadas -para determinar el excedente de operación-- no deberá exceder de $10.6 \%$ en 2015 , con ascenso gradual hasta $12.025 \%$ en 2018 . Queda así en evidencia nuevamente la ansiedad recaudatoria de la administración. A partir de 2015, Pemex, EPE, y sus filiales, deberán pagar el ISR y entregar a la SHCP, a partir del mismo año, el dividendo que ésta, anticipada y discrecionalmente, les determine desde mediados del año anterior.

Además de las obligaciones excesivas, se manifiesta el propósito de ejercer un control minucioso de las operaciones de Pemex desde la SHCP. A cuenta de los pagos provisionales, el asignatario efectuará pagos diarios, semanales y mensuales. Esto monta a que Pemex, amén de ser sostén cotidiano de la caja del fisco, deberá hacerse cargo del costo financiero e inflacionario del flujo de efectivo de aquél.

Para determinar las contraprestaciones a favor del Estado a que estarán obligados los contratistas, la Ley de Ingresos sobre Hidrocarburos rescata las cuatro figuras contractuales establecidas en los transitorios de la reforma constitucional: contratos de licencia, de utilidad compartida, de producción compartida y de servicios. Una seria deficiencia es que la legislación no define el "contrato de licencia", lo cual conduce a pensar que en realidad las licencias serán la forma preferida de contratación y que, dada la discrecionalidad prevaleciente en la legislación, se trata de una forma disfrazada de introducir las concesiones expresamente prohibidas en la Constitución. Además, diversos elementos del régimen fiscal para los contratos permiten suponer que el Estado asume en cierta medida los riesgos exploratorio y de desarrollo y, tal vez, también el de extracción.

Las contraprestaciones a favor del Estado son cuota contractual para exploración, regalías y tasa sobre utilidad operativa o sobre valor contractual, aplicables a los tres principales tipos de contrato. En el caso de licencias se recauda un bono a la firma. Se advierte una clara asimetría con el régimen de asignaciones en la forma de determinar el valor neto. Los "bonos a la firma" se establecieron deliberadamente en niveles "moderados" y las regalías en alrededor de 5\%, si bien se habla de "ajustes al alza" en casos de "rentabilidad extraordinaria".10

Preocupa también que las contraprestaciones iniciales (cuota para exploración, bono a la firma en el caso de licencias) resulten, a la luz de los niveles y tasas usuales en la práctica internacional, comparativamente modestas. Las demás contraprestaciones sólo se fijan hasta la determinación definitiva del reparto de la utilidad o excedente de la operación. Con ello, además de posponer el ingreso de recursos al FMP, el Estado mexicano compartiría, como ya se dijo, una proporción excesiva del riesgo exploratorio y de explotación con las compañías internacionales. Es decir, precisamente lo contrario de lo que se trataba de evitar.

Si bien es cierto que se requiere flexibilidad para operar en mercados abiertos con muchos actores experimentados e incluso muy poderosos, es indispensable hacerlo con base en algunos parámetros básicos de referencia, previamente definidos y públicamente conocidos, de modo que los procesos de licitación y adjudicación

10 Para mayor detalle sobre la materia ver "Exposición de motivos de la iniciativa de Ley de Ingresos sobre Hidrocarburos", y PUED, Grupo de Energía, "Ley de Ingresos sobre Hidrocarburos y el Fondo Mexicana del Petróleo” Documento de Trabajo, núm. 11b, PUED, UnAM, México, 2014. 
de contratos resulten menos casuísticos, ofrezcan mayor certidumbre y sean más transparentes. Los conceptos cruciales en esta materia son: el monto del bono a la firma (cuyos márgenes no quedaron definidos); la variable de adjudicación de los contratos; el monto de las regalías y, finalmente, las deducciones admisibles.

Un elemento hasta ahora no aclarado es el relativo a los criterios que se emplearán para determinar el "ajuste por utilidad extraordinaria". Preocupa la posibilidad de que la falta de definición previa pueda dar lugar a litigios que tornen aleatoria la captura de la renta económica de los hidrocarburos.

En resumidas cuentas, la intervención de los factores y fuerzas del mercado en los procesos licitatorios y de adjudicación de contratos se expresará en la puja de los interesados por superar los valores establecidos. La indispensable firmeza de las autoridades del Estado quedará de manifiesto, primero al rechazar aspirantes sin las calidades y cualidades establecidas; segundo al declarar desiertos los concursos cuando así corresponda; tercero al ejercer una estricta supervisión de los contratos adjudicados; y cuarto al cancelar los contratos por incumplimiento grave de los términos de los mismos y aplicar las sanciones económicas y legales que correspondan. 


\begin{tabular}{|c|c|c|c|c|c|c|}
\hline \multicolumn{7}{|l|}{ Cuadro 4} \\
\hline \multirow[b]{2}{*}{ Concepto } & \multicolumn{4}{|c|}{ Contratos } & \multirow{2}{*}{\multicolumn{2}{|c|}{ Asignaciones }} \\
\hline & De servicios & Licencias & $\begin{array}{l}\text { De utilidad } \\
\text { compartida }\end{array}$ & $\begin{array}{l}\text { Producción } \\
\text { compartida }\end{array}$ & & \\
\hline \multirow{4}{*}{$\begin{array}{l}\text { Contra- } \\
\text { prestación al } \\
\text { Estado }\end{array}$} & \multirow{4}{*}{$\begin{array}{l}\text { Definida para } \\
\text { cada contrato } \\
\text { considerando } \\
\text { estándares } \\
\text { de la } \\
\text { industria }\end{array}$} & $\begin{array}{l}\text { Bono a la } \\
\text { firma } \\
\text { (discrecional) }\end{array}$ & \multicolumn{2}{|l|}{ No aplica } & \multirow[t]{2}{*}{ No aplica } & \\
\hline & & $\begin{array}{l}\text { Cuota para } \\
\text { exploración } \\
\text { (discrecional) }\end{array}$ & \multicolumn{2}{|c|}{$\begin{array}{l}\text { Cuota para exploración } \\
\text { (\$Mex } 1,150 \text { y } 2,750 \text { por km2) }\end{array}$} & & $\begin{array}{l}\text { Derecho de } \\
\text { exploración de } \\
\text { hidrocarburos }\end{array}$ \\
\hline & & \multicolumn{3}{|c|}{$\begin{array}{l}\text { Regalía: tasa sobre valor de } \\
\text { extracción, según precio de los } \\
\text { hidrocarburos extraídos }\end{array}$} & \multirow{2}{*}{$\begin{array}{l}\text { Derecho sobre } \\
\text { valor de } \\
\text { extracción, } \\
\text { según precio } \\
\text { de los } \\
\text { hidrocarburos } \\
\text { extraídos } \\
65 \% \text { del valor } \\
\text { de los hidro- } \\
\text { carburos } \\
\text { extraídos } \\
\text { menos } \\
\text { deducciones } \\
\text { autorizadas }\end{array}$} & $\begin{array}{l}\text { Derecho de } \\
\text { extracción de } \\
\text { hidrocarburos }\end{array}$ \\
\hline & & $\begin{array}{l}\text { Tasa } \\
\text { sobre valor } \\
\text { contractual } \\
\text { (discrecional) }\end{array}$ & \multicolumn{2}{|c|}{$\begin{array}{l}\text { Participación en utilidades } \\
\text { operativas } \\
\text { (mecanismo de ajuste) }\end{array}$} & & $\begin{array}{l}\text { Derecho por } \\
\text { la utilidad } \\
\text { compartida }\end{array}$ \\
\hline ISR & \multicolumn{6}{|c|}{$\begin{array}{l}\text { Deducción por inversiones: } 100 \% \text { en exploración y recuperación secundaria; } \\
25 \% \text { en extracción y } 10 \% \text { en infraestructura }\end{array}$} \\
\hline $\begin{array}{l}\text { Impuesto por } \\
\text { exploración } \\
\text { y extracción }\end{array}$ & \multicolumn{6}{|c|}{ Exploración: \$Mex 1,500 y extracción \$Mex 6,000 por km2 } \\
\hline $\begin{array}{l}\text { Contra- } \\
\text { prestación al } \\
\text { contratista }\end{array}$ & $\begin{array}{l}\text { Definida para } \\
\text { cada contrato } \\
\text { considerando } \\
\text { estándares } \\
\text { de la indus- } \\
\text { tria }\end{array}$ & $\begin{array}{l}\text { Transmisión } \\
\text { onerosa }\end{array}$ & $\begin{array}{l}\text { Recupera- } \\
\text { ción de cos- } \\
\text { tos, gastos e } \\
\text { inversiones y } \\
\text { participación } \\
\text { en utilidades } \\
\text { operativas }\end{array}$ & $\begin{array}{l}\text { Recupera- } \\
\text { ción de cos- } \\
\text { tos, gastos e } \\
\text { inversiones y } \\
\text { participación } \\
\text { en utilidades } \\
\text { operativas }\end{array}$ & No aplica & \\
\hline
\end{tabular}

\section{Acentuar el sesgo exportador}

La orientación hacia la exportación primaria de la actividad petrolera en México, que se examinó anteriormente, se verá fortalecida si se cumplen, aunque sea en parte, los objetivos proclamados de la reforma energética, en especial el relativo a conseguir un ascenso importante y relativamente rápido de los volúmenes extraídos. Habría de persistirse entonces en una trayectoria que concentra su contribución en facilitar el financiamiento de importaciones crecientes y hacer posible que se mantenga la dependencia de las finanzas públicas respecto de los ingresos petroleros. No puede preverse que la vulnerabilidad externa del país disminuya como resultado de la reforma energética, sino más bien hay que esperar que se acentúe y torne más aguda. 
A pesar de lo anterior, el tema del destino de la producción mexicana de crudo, en términos de la proporción de los volúmenes extraídos que va a canalizarse a los mercados internacionales, fue quizá el que menor atención recibió en los doce meses transcurridos entre el anuncio de la iniciativa original y la promulgación de las leyes reglamentarias de la reforma constitucional.

Una de las muy escasas metas cuantificadas de la reforma para el sector petrolero es la de extracción total de hidrocarburos. Apareció desde la primera propuesta de reforma constitucional, dada a conocer en agosto de 2013, y se limitó a dos conceptos: producción de petróleo crudo y producción de gas natural, previendo haber alcanzado para ambos aumentos importantes en dos momentos del futuro: 2018, fin de la actual administración, y 2025. Los montos de producción esperados con la reforma, apuntan a una tendencia ascendente hasta 2018 que se acelera aún más en los siete años siguientes, hasta 2025. Estas previsiones contrastan de manera diametral con la trayectoria descendente de los volúmenes de producción antes del parteaguas que se supone marca la reforma. Alcanzar dichos objetivos supondría revertir las trayectorias descendentes que han caracterizado a la producción de hidrocarburos en México, durante los últimos doce años al menos.

\begin{tabular}{|c|c|c|c|c|c|}
\hline \multicolumn{6}{|c|}{$\begin{array}{l}\text { Cuadro } 5 \\
\text { Con la reforma: giro esperado en la producción de hidrocarburos }\end{array}$} \\
\hline Concepto & 2001 & 2009 & 2013 & 2018 & 2025 \\
\hline Crudo / mb/diarios & 3127.0 & 2601.5 & 2522.1 & 3000.0 & 3500.0 \\
\hline Crudo / mmb/anuales & 1125.7 & 936.5 & 908.0 & 1080.0 & 1260.0 \\
\hline Gas / mmp3/diarios & 7315.0 & 7030.7 & 6370.3 & 8000.0 & 10400.0 \\
\hline Gas / mmmp3/anuales & 2633.4 & 2531.1 & 2293.3 & 2880.0 & 3744.0 \\
\hline \multicolumn{6}{|c|}{$\begin{array}{l}\text { b - barriles / p3 - pies cúbicos / bpe - barriles de petróleo equivalente. } \\
\text { m - miles / mm - millones / mmm - miles de millones. } \\
\text { fuente: } 2001,2009 \text { y 2013: Informes anuales de Pemex a la Securities and Exchange Commis- } \\
\text { sion (SEC) de Estados Unidos / } 2018 \text { y 2025: Con base en datos de la Iniciativa de reforma consti- } \\
\text { tucional en materia energética, agosto de } 2013 \text {. }\end{array}$} \\
\hline
\end{tabular}

Apréciese la magnitud del giro, de $180^{\circ}$, podría decirse: tras abatirse en 605 mil barriles la producción diaria entre 2001 y 2013, se espera que la extracción de crudo crezca en casi un millón de barriles diarios entre 2013 y 2025; para el gas se pronostica, en los próximos doce años, un salto de más de 4 mil millones de pies cúbicos en la producción diaria, tras un abatimiento de casi mil millones en los últimos doce. La amplia documentación oficial relativa a la reforma energética permite prever que, en su mayor parte, la producción adicional provendrá de los agentes privados que participen en el sector.

La actividad internacional de Pemex es tratada de manera particularmente detaIlada en los informes presentados a la Comisión de Valores y Bolsas, la SEC, de Estados Unidos. Se declara invariablemente en los diversos informes anuales que la actividad 
internacional de Pemex se realiza mediante el Grupo PMı. ${ }^{11}$ Una de las consecuencias de la reforma será abrir a la participación de empresas privadas nacionales y foráneas la actividad de comercialización internacional de Pemex. Sobre este asunto, el Grupo de Energía del Programa Universitario de Estudios del Desarollo (PUED) ha hecho notar que resultaría preferible no incrementar el número de intermediarios que participa en las ventas externas del crudo que produzca Pemex, por sí mismo o asociado con otras empresas. ${ }^{12}$ Con base en los reportes a la SEC se construye una visión clara del marcado sesgo exportador de la industria petrolera mexicana.

\begin{tabular}{|c|c|c|c|c|}
\hline \multicolumn{5}{|c|}{$\begin{array}{l}\text { Cuadro } 6 \\
\text { El sesgo exportador de la industria petrolera mexicana }\end{array}$} \\
\hline Concepto & Unidad & 2001 & 2009 & 2013 \\
\hline Reservas probadas de crudo y condensados & & 18767.0 & 11691 & 11079 \\
\hline Reservas desarrolladas & Mh & 12622.0 & 8167 & 7360 \\
\hline Reservas no desarrolladas & & 6145.0 & 3524 & 3719 \\
\hline Producción anual de crudo & $\mathrm{Mb}$ & 1125.7 & 936.5 & 908.0 \\
\hline Producción diaria de crudo & $\mathrm{mbd}$ & 3126.9 & 2601.5 & 2522.1 \\
\hline Años de cobertura de las reservas & unidades & 16.7 & 12.5 & 12.2 \\
\hline Costo unitario producción crudo & Dls / b & 3.34 & 4.85 & 7.91 \\
\hline Consumo aparente anual de crudo & $\mathrm{Mb}$ & 493.9 & 496.5 & 480.0 \\
\hline Exportación anual crudo & $\mathrm{Mb}$ & 631.8 & 440.0 & 428.0 \\
\hline Valor exportaciones crudo & MMDIs & 11896.0 & 25605.4 & 42723.2 \\
\hline Valor unitario exportaciones crudo & Dls / b & 18.83 & 58.19 & 99.84 \\
\hline Exportación / producción crudo & $\%$ & 56.1 & 47.0 & 47.1 \\
\hline Razón exportación / reservas & $\%$ & 3.3 & 3.8 & 3.9 \\
\hline Producción anual de gas & MMp3 & 2633.4 & 2531.1 & 2293.3 \\
\hline
\end{tabular}

$\mathrm{Mb}$ - millones de barriles / mbd - miles de barriles diarios / Dls - dólares de EE UU / MM - miles de millones / p3 - pies cúbicos fuente: Reportes anuales de Pemex a la Comisión de Valores y Bolsas de ee uu, varios años.

11 Estos documentos pueden consultarse en la página web de Pemex (www.pemex.com). Por ejemplo, el informe de 2013 indica (p 50): "El Grupo PMI maneja las ventas externas de nuestro petróleo crudo y adquiere en los mercados internacionales los productos petroleros que importamos para satisfacer la demanda interna. La compra-venta de productos petroleros (refinados, petroquímicos y gas LP) en los mercados internacionales se maneja a través de PMI Trading. PMI Trading también realiza actividades de comercialización de terceros, contratación de servicios logísticos y manejo de riesgos."

12 En efecto, la reforma prevé "que la CNH contrate con Pemex, con alguna de sus filiales, con otra EPE O con particulares, mediante licitación, la prestación del servicio de comercialización de hidrocarburos. Se propone también que, por los primeros tres años tras la entrada en vigor de la Ley, Pemex continúe realizando la comercialización, 'en tanto se establecen las condiciones para licitar el servicio'. Es curioso, por decir lo menos, que se suponga que ya existen condiciones para licitar de inmediato los contratos de exploración y extracción, y que se requieran hasta tres años - uno de los plazos más largos previstos en la iniciativa-para una actividad comparativamente sencilla: la comercialización. Sin duda, las razones son otras." PUED, Grupo de Energía, "Las actividades extractivas en la iniciativa de Ley de Hidrocarburos", documento de trabajo 11a, UnAm, México, 10 de junio de 2014, p. 33. 
Un primer elemento a destacar es el estancamiento del consumo aparente nacional (producción menos exportaciones más importaciones) de crudo en los últimos doce años, que lo mantiene en una banda ligeramente inferior a los 500 millones de barriles anuales. Hacia el futuro, la previsión de crecimiento económico asociada a la reforma energética es modesta: un punto adicional para 2018 y dos puntos adicionales para 2025. Si se supone (sin conceder, desde luego) que estas previsiones se tornen realidad, no cabe esperar un aumento dramático en el uso nacional de crudo, frenado por la parálisis de la capacidad de refinación. Los informes de Pemex a la SEC revelan que la destilación atmosférica instalada - de la que se obtienen, entre otros, gasolinas, kerosene y diesel- se mantuvo por debajo de $1.6 \mathrm{mmbd}$ entre 2001 y 2010 para situarse en $1.69 \mathrm{mmbd}$ en los últimos tres años (2011-2013). Es probable que no se registren aumentos significativos antes de 2018. Es incierto el futuro del proyecto de una nueva refinería en Tula, que añadiría alrededor de $250 \mathrm{mbd}$ a la capacidad instalada de procesamiento de crudo pesado y produciría alrededor de 163 mbd de gasolinas - menos de la mitad del volumen de gasolina importado en 2013 (357 mbd) - y $117 \mathrm{mbd}$ de diesel. ${ }^{13}$ En suma, las cifras previsibles de crecimiento económico, uso nacional de crudo y capacidad de refinación llevan a esperar que el volumen adicional de crudo que se logre extraer con la reforma se destinará, casi fatalmente, a la exportación.

El documento que recoge el resultado de la ronda cero incluye dos datos significativos para el tema en discusión: las reservas y recursos prospectivos otorgados establecen "un piso para que Pemex pueda producir del orden de $2.5 \mathrm{mmbd}$ en los próximos 20.5 años" [p. 5]; y "[c]on las primeras 120 asignaciones entregadas a Pemex, se cubre $71 \%$ de la producción actual de petróleo, y $73 \%$ de la producción nacional de gas natural" (énfasis y anglicismos en el original). ${ }^{14}$ La afirmación de que las asignaciones autorizadas establecen un límite inferior a la producción de Pemex similar a su producción actual (2013) y que ésta podrá mantenerse en los próximos dos decenios y seis meses, no es congruente con el señalamiento de que las mismas cubren menos de tres cuartas partes de la producción actual de petróleo y gas. En otras palabras, como se dijo antes, cualquier monto adicional que se llegue a producir en los próximos años provendrá de los nuevos actores a los que la reforma abre las puertas. 15

Otro ángulo hasta ahora no discutido de la supuestamente acrecida capacidad de producción petrolera mexicana, que los reformadores esperan que llegue a un millón de barriles diarios hacia 2025, es el impacto de que la mayor parte de la misma se destine al mercado internacional. En cuanto a volúmenes: no hubo dificultad para colocar la declinante exportación mexicana en los últimos doce años habida cuenta de su concentración en el mercado de Estados Unidos, al que se destinaron entre

13 Informe anual de Pemex a la Comisión de Valores y Bolsas (SEC), 2013, loc. cit.

14 sener, "Resultado de la Ronda Cero", página web de la sener, pp. 5 y 17.

15 En realidad las declaraciones oficiales han creado confusión. Entrevistada sobre las expectativas de producción adicional, la subsecretaria de Hidrocarburos de la sener declaró: "Primer barril de petróleo privado, antes de que acabe el sexenio" (El financiero, México, 20 de agosto de 2014). De ser así, no habrá producción adicional significativa en los próximos tres o cuatro años. 
tres cuartas y cuatro quintas partes del total. El volumen adicional esperado en los próximos doce, que es marginal en términos del mercado mundial, tendría cabida en el mismo país, a menos de que su producción no convencional (thight oil y shale gas) aumente en forma mucho mayor a la esperada. La AIE considera que "la prontitud con la cual la producción de hidrocarburos no convencionales se convierta, duplicando la experiencia estadounidense, en un fenómeno mundial, es todavía una cuestión sin respuesta". 16

Las cosas son diferentes del lado de los precios. Como se advierte en el cuadro 2 , el valor medio del barril mexicano exportado se multiplicó casi por cinco en los últimos doce años. ¿Cabe esperar un comportamiento similar en los próximos doce? La mayor parte de las respuestas van por la negativa, aunque en realidad nadie pronostica los precios de exportación del crudo en un horizonte de esa magnitud, con multitud de imponderables. Pero más que de la perspectiva de largo plazo, los precios del crudo en los mercados mundiales dependen de los balances entre demanda y suministros en el muy corto plazo, año tras año-además de las disrupciones políticas ante las que son particularmente sensibles. En el lapso de 2013 a 2025, en ausencia de políticas intensas y efectivas de sustitución de combustibles fósiles asociadas al cambio climático, la AIE espera una fuerte expansión de la demanda mundial de crudo, estimada en 387 mmTon, concentrada desde luego en el mundo en desarrollo, pues la demanda de la Organización para la Cooperación y el Desarrollo Economicos (OCDE) se abatiría. En cambio, entre 2025 y 2035 ese aumento medio anual se reduciría a $121 \mathrm{mmTon}$, por el menor crecimiento en China y en el mundo en desarrollo y una nueva caída, aún más pronunciada, en la ocDE. Una reducción de dos tercios en el incremento de la demanda global de crudo sin duda tendría un impacto negativo importante sobre los precios después de 2025. Si fuese después de este año cuando se manifestase el mayor efecto de expansión de la producción y exportación de crudo mexicano originado en la reforma energética de 2014, vendría un poco tarde respecto de los comportamientos esperados del mercado mundial.

En suma, entre 2001 y 2013 las caídas en el volumen exportado se vieron más que compensadas por los incrementos en los precios y hubo ingresos de divisas rápidamente crecientes que no se aprovecharon para el desarrollo. Entre 2014 y 2025 - el horizonte de planeación de la reforma - no hay certeza de que se consigan los incrementos esperados y, por tanto, sus efectos positivos sobre el crecimiento. Si los aumentos se registran después de 2025 pueden coincidir con una etapa de cotizaciones decrecientes ante la posible caída mundial -o por lo menos de los países avanzados - de la demanda de combustibles fósiles.

\section{Conclusiones}

Además de las relacionadas con cuestiones de procedimiento legislativo, a las que se prefirió no aludir en este texto, se señalaron diversas deficiencias genéricas, además de numerosos defectos puntuales de los nuevos ordenamiento legales sobre hidro-

16 International Energy Agency, World Energy Investment Outlook, Special Report, París, 2014, p. 80 (www.iea.org). 
carburos: no aseguran el ejercicio cabal de la rectoría del Estado sobre la actividad extractiva y de transformación industrial de los hidrocarburos; no ofrecen certeza de retener para la nación la renta petrolera; no garantizan una regulación eficaz de los agentes públicos y privados que intervendrán en la industria; no abren una perspectiva cierta de desarrollo de Pemex como empresa productiva del Estado; establecen una preferencia abusiva para la actividad extractiva sobre los demás posibles usos del territorio; y, prevén el tratamiento separado de los hidrocarburos en materia ambiental.

La rectoría del Estado -concepto aludido en la exposición de motivos de la iniciativa de Ley de Hidrocarburos, pero ausente de su articulado- únicamente se materializa en "la planeación y conducción de las actividades de exploración y extracción, así como en la selección de los contratistas"; se expresa en los requisitos y características de los contratos de exploración y extracción, insuficientemente definidas, y la ejercen dos secretarías, Energía y Hacienda, y un órgano autónomo, la Comisión Nacional de Hidrocarburos. Las previsiones en materia de planeación energética, contenida en el artículo relativo a la SENER de la Ley Orgánica de la Administración Pública Federal, destinada a orientar las acciones del Estado para regir el sector de energía, en general, y la industria petrolera en particular, se plantean en términos muy generales, discursivos más que instrumentales.

Retener para la nación la renta petrolera no es un resultado cierto del régimen fiscal propuesto en la Ley de Ingresos de Hidrocarburos. En realidad, ésta se orienta a otras dos finalidades: establecer un modelo tributario para la actividad petrolera ejercida por particulares que se constituya en un factor de atracción y estímulo a las inversiones de éstos, en especial de las empresas petroleras y de servicios foráneas. La segunda es mantener a Pemex, ya convertida en EPE, como el principal contribuyente a lo largo de lapsos de transición en algunos casos muy extensos y, más adelante, mantener una exacción permanente, equivalente a $4.7 \%$ del PIB, independiente de los resultados específicos que se obtengan en el ejercicio fiscal de que se trate. Hay un agudo contraste entre el régimen tributario estricto que gravará las asignaciones, a cargo sólo de Pemex y otras EPE, y el régimen laxo y casuístico que se estatuye para determinar las contraprestaciones a cargo de los contratistas.

El régimen de regulación que se aprobó es a la vez complicado y disperso, con dos órganos reguladores y con muy diversas disposiciones insertas en varias otras leyes, además de la relativa a los organismos reguladores, y a cargo de otras autoridades. Puede desembocar en un auténtico laberinto regulador, tanto desde el punto de vista del número de disposiciones como de la variedad de instituciones implicadas en el ejercicio de la acción reguladora. Es claro que esta dispersión, tanto funcional como institucional, disminuirá la eficacia de la regulación, al tiempo que podría facilitar, en muy diversos momentos, la captura de las entidades reguladoras en un sector que, por obra de la reforma misma, se abre a la participación de corporaciones cuya conducta habitual procura eludir las disposiciones regulatorias o influir en su contenido y alcance, en función de sus intereses corporativos. 
Es paradójico el régimen de excepción para Pemex que contiene su ley orgánica. Por una parte, lo coloca en desventaja en las condiciones de competencia con los participantes privados y le plantea exigencias que no encuentran correlato en las que se establecen para los agentes privados. A la vez, se excede en las atribuciones de gestión autónoma que concentra en su consejo de administración y su dirección general. Más que una empresa productiva del Estado se establece una empresa al servicio del gobierno en turno y manejada por éste con sistemas autorreferenciados de vigilancia y rendición de cuentas.

Han abundado las denuncias de la preferencia excesiva a la actividad extractiva que se establece y que permitiría atropellar derechos de propietarios de predios, como las comunidades indígenas, y el desarrollo de otras actividades económicas, la pesca entre ellas.

Es desmesurado el procedimiento de decidir las cuestiones ambientales de los hidrocarburos a través de una agencia ad hoc, prácticamente al margen de la legislación ambiental. Se fundamenta en nociones obsoletas de protección, que la legislación mexicana en la materia dejó atrás desde hace un cuarto de siglo al adoptar la actual Ley General del Equilibrio Ecológico, basada en esta noción más amplia y universal. Al crear una institución específica y medidas de alcance sectorial parece querer liberarse al rápido desarrollo de la exploración y extracción de cualquier "prejuicio ambiental".

Incluso un planteamiento tan esquemático deja en claro el balance negativo de una reforma constitucional y legal que lesiona el interés nacional. Ante esta situación cobra particular relevancia la referencia introductoria a la demanda de una consulta popular para revertir la reforma energética, ya presentada por diversos grupos de ciudadanos. Este planteamiento satisface los supuestos de la disposición constitucional y de la ley reglamentaria correspondiente, por lo que es de esperarse que el Congreso de la Unión la convoque para celebrarla en la jornada electoral federal de junio de 2015. 